

\section{TUDO \\ VAI MUDAR}

| POR STEFANO CASELLI

\section{Para enfrentar desafios completamente novos, as escolas de negócios estão identificando estratégias inovadoras de forma a se destacarem internacionalmente.}

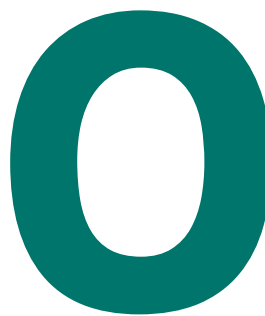

mundo está mudando. Paradigmas bem estabelecidos, tais como globalização, mobilidade do capital humano sem qualquer limite e livre acesso aos mercados de trabalho, estão sendo agora colocados em discussão. Para as escolas de gestão empresarial, essas tendências podem afetar o modelo de negócio, mas, sobretudo, precisam ser analisadas, compreendidas e interpretadas de forma que se consiga dar uma orientação mais efetiva à nova geração e, humildemente, à sociedade como um todo. Além disso, as gerações mais jovens têm em mente paradigmas que a própria sociedade não entende completamente, e sua energia e capacidade de se conectar ultrapassando quaisquer barreiras são a esperança, ou ainda, a certeza, de que o mundo será melhor. E avançaremos ainda mais se os seres humanos puderem se tornar mais inclusivos e mais abertos para ouvir as necessidades globais e locais.

Nas escolas de negócios, o ciclo de vida dos diferentes programas está evoluindo, e uma grande mudança está para acontecer. O Master in Business Administration (MBA) é hoje um programa maduro, reconhecido mundialmente (ou estará decadente?), e três tendências vão transformá-lo. Primeiramente, a modalidade de mestrado científico está se tornando a mais atraente, e os empregadores estão cada vez mais procurando candidatos com esse aprofundamento. Em segundo lugar, mais candidatos sêniores estão procurando um MBA executivo, e eles dirigem suas escolhas para modalidades mais sêniores. Terceiro, o programa de MBA vai permanecer, mas o que fica claro é que está em curso um processo de busca por soluções menos arriscadas e de consolidação do mercado, o que faria com que somente as principais escolas oferecessem programas de MBA no futuro. Isso é verdade principalmente na Europa, mas sinaliza que é necessário também um debate mais global entre os acadêmicos das principais escolas e os gestores. No debate, também deve entrar a questão do papel que o ensino virtual poderia ter no futuro: o formato online será complementar ou superará o papel das tradicionais aulas em classe?

\section{DENOMINADORES COMUNS}

Por outro lado, as escolas estão convergindo para algumas características comuns (e bem identificadas) na sua oferta de programas para garantir que sejam reconhecidas como players globais em um mercado global. A cobertura de todos os setores da educação superior - desde estudantes até profissionais experientes - é um denominador comum para as escolas. Mesmo aqueles players que estão fora do bacharelado podem analisar o lançamento de um programa de graduação, assim como aqueles que não têm educação executiva podem criar um MBA. Também as escolas de gestão empresarial "pura", como o Instituto de Estudos Superiores da Empresa (IESE) e o Instituto Europeu de Administração de Empresas (Insead), estão entrando no mercado do mestrado 
científico, como também as universidades americanas. A presença nos três mercados - graduação, educação executiva e pós-graduação científica - gera sinergias, diversifica o "risco e o retorno" e fortalece a relação com as corporações, o que facilita o posicionamento e o levantamento de fundos. E uma escola pode ainda desenvolver uma "graduação dupla", combinando, em soluções inovadoras, diferentes programas.

Outros fatores que representam a identidade de um player global ou internacional são: a oferta da maioria dos cursos em inglês, a variedade de programas de pós-graduação, a proporção de estudantes internacionais bem maior do que a de alunos do país, uma rede muito forte e diversificada de parceiros para intercâmbio e para graduação dupla, a relevância das redes e da participação nelas. As universidades americanas são parcialmente diferentes por causa do seu papel marginal (mas que está mudando rapidamente) nos programas de pós-graduação para estudantes recém-graduados e sem experiência e no uso da rede internacional, que parece polarizada entre um grupo de usuários "leves", ou seja, que participam de programas de intercâmbio e de graduação dupla eventualmente, e um grupo de usuários "pesados", aqueles que usam com frequência esses programas (ou seja, em patamar comparável ao das universidades fora dos Estados Unidos). Todos esses fatores estão criando um parâmetro de mercado que não significa "homogeneidade", mas sim um desafiador "padrão mais alto" de competição.

Ênfase especial precisa ser dada à porcentagem de estudantes internacionais. Esse parâmetro aparece como um direcionador-chave para os rankings de escolas de negócios. A porcentagem parece depender do "prestígio" da universidade, o que lhe permite ter vantagem em relação aos concorrentes. Esse "prêmio" é estabelecido por meio de um complexo conjunto de fatores, entre os quais se destacam: a atratividade do país e do seu mercado de trabalho, a atratividade da cidade, a presença de ligações históricas e linguísticas com os estudantes estrangeiros, a rede internacional capaz de oferecer experiências no exterior, a qualidade dos acadêmicos e da pesquisa, a qualidade dos programas, o programa de isenção de taxas de matrícula, a qualidade dos serviços e das instalações, os próprios rankings de escolas de negócios. Somente em casos muito específicos uma universidade pode ser projetada a partir do zero para ser, por definição, um atrativo para estudantes estrangeiros.

\section{ABORDAGENS PRÓPRIAS}

Também abordagens diferentes despontam juntamente com as características comuns já mencionadas. Experiências para criar uma plataforma de educação aberta são muito atraentes, mas devem ser avaliadas com muito cuidado.
Outro aspecto do processo de hibridização está relacionado à combinação de tópicos e conteúdos muito diferentes. Em nível de graduação, escolas canadenses (por exemplo, Universidade da Colúmbia Britânica - UBC e Universidade McGill) e australianas (por exemplo, Universidade Monash) começaram a projetar programas de administração e economia abertos para inserir módulos e soluções mistas relacionadas ao STEM - sigla em inglês que se refere ao campo de conhecimento composto de ciências, tecnologia, engenharia e matemática e até mesmo medicina.

Outro aspecto-chave é o destaque crescente das universidades chinesas. Sua ambição é a legitimação por meio do crescimento nos rankings mais importantes e de uma presença mais ativa no mercado de trabalho dos professores universitários (mesmo que esse caminho a ser trilhado ainda seja longo). A atenção das universidades chinesas ao mercado europeu é muito grande e está levando a um aumento de acordos não apenas para intercâmbios, mas também para graduação dupla e para programas combinados.

Finalmente, o papel das redes está cada vez mais importante. As associações e redes não são algo novo no mercado, uma vez que a Global Alliance in Management Education (CEMS) e a Partnership in International Management (PIM) nasceram há tempos. Nos últimos anos, vêm surgindo novas soluções, como a Global Network for Advanced Management (GNAM) e novos projetos, o que pode levar a atividades conjuntas mais profundas que vão afetar os produtos centrais, como os programas de graduação.

Um último tema que gostaria de mencionar é a mudança das regras que ocorre na Europa. A União Europeia lançou o Projeto das Universidades Europeias, para a criação de consórcios de campi compartilhando alunos, pesquisas e professores. Esse plano pode afetar profundamente o mercado. A presença de um espaço de livre circulação, de uma graduação europeia e de programas de financiamento feitos sob medida para essa mudança é hoje uma opção sobre a mesa que precisa ser monitorada nos próximos meses.

Nesse complexo cenário, as principais universidades estão identificando as suas estratégias para enfrentar os desafios. Para dar respostas cada vez mais eficientes às necessidades das futuras gerações e dos empregadores, as escolas também precisam criar seu próprio futuro. É uma evolução, porém, em sua profundeza, é uma revolução. Como as grandes escolas são capazes de fazer.

\section{*Artigo traduzido da versão original em inglês.}

STEFANO CASELLI > Diretor para Assuntos Internacionais e Professor de Finanças da Universidade Luigi Bocconi > stefano.caselli@unibocconi.it 